\title{
An Exploration of Learning Styles Preferences of Higher Education Students in Pakistan
}

\author{
Fakhra Yasmin \\ Academy of Educational Sciences, Huazhong University of Science \& Technology \\ Wuhan, P.R. China \\ E. Mail: fakhrayasmin@ue.edu.pk
}

\begin{abstract}
Ahsan Akbar
School of Accounting and Finance, Zhongnan University of Economics \& Law

Wuhan, P.R. China

E. Mail: ahsan_finance@ hotmail.com

Zhang Yan (Corresponding Author)

Assistant Professor, Academy of Educational Sciences

Huazhong University of Science \& Technology, Wuhan, P.R. China

E. Mail: zhangyan1981@ @ust.edu.cn
\end{abstract}

Received: December 02, 2016 Accepted: December 18, 2016 Published: January 03, 2017

doi:10.5296/ijld.v6i4.10414 URL: http://dx.doi.org/10.5296/ ijld.v6i4.10414

\begin{abstract}
Every individual adopts a unique way to obtain knowledge and this way of acquiring knowledge is known as learning style. These learning approaches of the students can significantly influence their learning outcomes. The aim of this study was to examine the learning styles of Master level students enrolled in Education programs of the public sector universities in southern Punjab region of Pakistan. The study findings reveal that students majoring in Education practice multiple learning styles to accomplish their academic goals endeavors. Moreover, assimilating was the most practiced learning style by the sampled students. The result of ANOVA posits that there are significant differences in learning styles adopted by the students of different universities. The findings of this study provide useful
\end{abstract}


information about the learning style preferences of the social science students and postulate that the choice of university significantly influences the learning style adaptation of students.

Keywords: Learning, Learning styles, Assimilating, Converging, Higher education, Pakistan

\section{Introduction}

Learning has been variously described in the literature. Battersby and Gordon (2006) described learning as "a transformation that occurs in the brain mainly for problem-solving" [1]. It is an internal process that leads to behavioral change. Learning can also be elaborated as extension and clarification of meanings of one's experience. It is an organized, internal process of testing ideas relevant to the problems. Learning goes on throughout life as it is a personal and natural process. Becoming a lifelong learner is to become more alive, more open to new experiences, ideas, and insights.

Learning styles define people's characteristics and their ways of information processing, feeling, and behaving toward learning situations. In other words, learning styles refer to those preferences, dispositions, and tendencies that influence one's learning [2]. Knowledge of learning styles is termed useful in becoming an effective learner and educator. Students are unique in their ways to have a tendency in adopting different styles of learning for the acquisition and assimilation of knowledge. It has been indicated that both low and average achievers earn higher scores on standardized achievement and aptitude tests when they are taught within the realm of their learning [3]. Many studies have demonstrated significant academic gains of adopting the preferred learning approach. In one study, the undergraduate physical therapy students who were forced to learn in their least preferred ways experienced higher anxiety levels and more negative attitude towards the instructions than a comparable group that learned in their most preferred ways [4].

Learning styles of an individual stem from three main components of personality that are cognitive, affective, and the environmental components which effects overall learning experience [4].

\subsection{Cognitive Components of Learning Style}

When we go about activities such as working, playing and learning, we use our mind and our senses in consistent ways. We have acquired preferred patterns of perceiving, remembering, thinking and problem-solving. Complex cognitive strategies, structures and controls are at work that enable us to deal successfully with the stimuli that come our way. These cognitive mechanisms enable us to conceptually organize our environment and help us in shaping our behavior. These cognitive components constitute a learning style [5].

\subsection{Affective Components of Learning Styles}

It has been well documented that expectations of success play an important role in learning. If a school teacher expects a pupil to do well, the pupil tends to do so. Some people have learned to set demanding yet realistic goals for themselves. Others have not, either greatly 
underestimating or overestimating of what they can accomplish. Thus, expectation and motivation play an important role in the learning process [2]. Expectations and motivations are affected by one's reaction toward the subject or skill to be learned. Previous experience in schooling with a similar subject can strongly shape that reaction. For this reason, efforts to diagnose learning style may include assessing the individual's preferred areas of interest [4].

\subsection{Environmental Components of Learning Styles}

Component of learning style includes considerations that range from such a specific matter as preferred room temperature to the amount of affiliation and emotional support learners find helpful in the immediate environment [3]. Another consideration is the level of sound, especially how much external sound one can tolerate or block out during the learning process. Some people actually prefer music or similar background sound to silence, others are distracted by external sound, while still others can accommodate to either condition [5]. Light is a factor that appears to affect fewer people than does sound, though a small percentage of people have quite negative reactions to strong light. For others, the bright light seems to serve as an energizer. Moreover, People also differ in the extent to which they prefer an informal and supportive climate as opposed to a more formal and impersonal one.

There are two main directions to the learning process in which the students follow these two ways to learn, the first way to learn is the acquisition of new information and second is the information processing after it is acquired [6]. David Kolb combined these directions to shape learning process that determines an individual's own style of learning. Learning styles identified by him are termed as assimilating, converging, diverging, and accommodating. He postulates that Assimilators obtain their learning by thinking and watching. Converging learning style adopters learn by thinking and doing. However, people opting for diverging style learn by feeling and watching while accommodators learn through feeling and doing [7].

The person who is able to adopt an effective style of learning readily copes with the central task and meaningful activities. He/she can expect better results from investment in learning and education, more knowledge acquired in less time and almost certainly will enjoy the learning process more than one who goes about it aimlessly. Educators need to understand the pragmatic implications of the learning styles. This study is aimed at examining the learning styles practiced by the students majoring in Education in three universities of southern Punjab using a research questionnaire designed from the learning style inventory of Kolb. The empirical results of the study will uncover the dynamics of learning style practices of the social science students and will provide them guidelines in adopting an effective combination or sole style to boost their academic performance.

\section{Literature Review}

Considering the critical role of learning approaches in realizing desired educational outcomes, several empirical investigations have been conducted so far. Kolb's model is one of the theoretical perspectives which is applied to investigate the styles of learning. He believed that new experience and then analysis could help in the formation of concepts. After assimilating and organizing that concept, it may lead to new experiences based on the previous learning. 
In this model, learning is perceived as a process through which the transformation of experience can create knowledge [8].

Kolb's learning cycle integrate conceptualizing tendencies. Learning is portrayed as a cyclical process with four kinds of learning activities and the learning styles based on these activities. Learning styles named as diverging, assimilating, converging and accommodating. He developed a self-assessment instrument, the Learning Styles Inventory, to explore individual tendencies related to this theory. It measures how an individual learns from experience. The instrument yields a profile, or grid, that permits classifying people as accommodators, divergers, convergers, or assimilators.

A person dominantly following the converging style of learning is the one who relies on logical reasoning when making decisions, rather than deciding on the basis of feelings or emotions. Moreover, Convergers learn better by practicing examples and participating in the discussion, rather than looking at the tasks that others perform or by listening to the views of others. This demonstrates that the Convergers are active learners because they participate and explore new experiences by relating information with the concepts. They are not just the observers in their learning cycles. On the contrary, persons with accommodator dominant characteristics are the one who are action-focused and prefer to take the risk. They would carry out plans and experiments by involving themselves in new experiences. Whereas, divergers unite concrete experience and reflective observation and consider particular experience from a different viewpoint. They are imaginative and good at formulating ideas. Assimilators combine reflective observation and abstract conceptualization and progress in the formulation of theoretical frameworks [9].

Lieberman defined the Experiential learning cycle and claimed that learning can be optimized if the following conditions are met [10].

1. Individuals learn best when they are personally involved in the learning experience.

2. Knowledge of any kind has more significance when it is learned through one's own initiative, insight and discovery.

3. Learning is best when we are committed to aims that we have been involved in setting when our participation with others is valued and when there is a supportive learning framework. There are two distinctive approaches regarding the way students read learning materials, that are Surface-level and deep-level. Surface-level learning approach is the one in which students take a passive approach and are concerned with covering the content, amount or level of learning, finding the right answers and assimilating unaltered chunks of knowledge. On the contrary, the students with deep-level learning perspective pursue an active stance and are concerned with the core concept, try to find what lies behind the argument, the whole picture, points that are not clear and question the conclusions. The surface-level processors divert their attention; therefore, deep-level processors have an in-depth understanding of the underlying scenarios as compared to their surface-level counterparts. In general, those adopting 'deep' learning styles or approaches are more successful in exams [11]. 
Din explored the difference between learning style of students and their obtained grade points. The sample size was 820 taken from the Public sector Universities of Rawalpindi and Islamabad. Learning styles determined by administrating Kolb's learning style Inventory while achievement score was determined by results sheets from initial two semesters. The analyses indicated that Diverging learning style was adopted by the majority of students while the students who adopted multiple learning styles obtained higher grade points. The study concluded that there was a significant mean difference between learning styles and grade achievements of sampled students [12].

The students who apply multiple learning styles frequently in the process of learning perform better than their counterparts with one focal style of learning. In addition, average and low achievers obtain higher scores on standardized achievement tests when they are taught according to their preferred learning styles [9]. Likewise, Farooq and Regnier studied the role of learning styles in the quality of learning at University of the Punjab, Pakistan. The sample of this study consisted of 218 on-campus students registered in Master Degree Program. Analysis showed that majority of students preferred diverging and accommodating learning style [13].

From the context of Turkey, Caliskan and Kilinc conducted a study on learning styles and attitude of students towards the subject of social study. The learning styles preferences were determined through survey and attitude scale was used to determine the achievement level in the particular subject. The results of the study indicated a positive and statistically significant relationship between the learning styles of primary school students and their attitude towards social study course [14].

The influence of learning styles on scholastic achievement was observed by Bhatti and Bart. The sample consisted of 179 undergraduate students at the University of Minnesota. The Kolb's Learning Style Inventory was used as the instrument for data collection. The study found that assimilating learning style was the most adopted style [15]. Moreover, academic achievement was strongly influenced by learning style and gender. Akbari, Ghanbari and Talab argued that learning styles of the students shall be given due consideration especially while teaching a second language. Moreover, gender and individual differences also play an important role in influencing the student's learning ability [16].

To explore the difference between learning styles and cognitive abilities Mohammad, Heong, Hanafi and Kiong investigated a sample of 128 students from different schools in Malaysia. Results of their study indicate that Visual Learning style was the most preferred by the students. Based on their study findings they argued that successful learners are more likely to be those who are fine-tuned to the complexities of their learning style, who are perceptive of the requirements in learning and who have developed a range of strategies which they can apply according to their own style [17]. In a similar study from India, Vaishnav found that amongst the visual, auditory, and kinesthetic learning styles secondary school students is predominantly used kinesthetic learning style to accomplish their learning endeavors [18].

In a more recent study, Gokal evaluated the learning skills of the students enrolled in the faculty of education. Firstly, a pre-test was conducted to find the learning styles of students. 
Afterward depending upon the results of that pre-test effort was made to improve student's learning skills. A significant difference was observed between the pre-test and post-test learning of the sampled students. These findings suggested that academic performance can be enhanced by opting the appropriate learning style [19].

\section{Material And Methods}

The objective of this study was to identify the learning styles adopted by the students of Master in Education enrolled in three public sector universities of southern Punjab during 2012-15. The survey research technique was used and learning styles of the students were identified on the basis of their response on Five points Likert scale. Learning Styles Inventory established by David Kolb (1985) was used as a guideline to design the research instrument. Our final sample comprises 397 respondents including both genders of which 119 respondents were from Bahauddin Zakariya University (BZU), Multan, 88 students from University of Education (UE), Multan Campus and 190 students from The Islamia University Bahawalpur (IUB). SPSS was used for data analysis. Descriptive statistics, correlation, and Analysis Of Variance (ANOVA) techniques were used to figure out the learning styles adopted by the sampled students, to identify the differences in learning styles of the students studying in sampled Universities, and to compare the effectiveness of these learning styles.

\section{Results And Discussion}

Statistical results are obtained by using descriptive statistics, factor matrix correlation, mean comparison, and ANOVA. The results are discussed below. The descriptive statistic is an important tool for research in social sciences because it provides the general behavior of the survey data. The table below highlights the results of descriptive statistics about the score of learning styles that student obtained on the attitude scale.

Table 1: Descriptive Statistics of the Students Responses

\begin{tabular}{|l|l|l|l|l|l|l|}
\hline Respondents & N & Range & Maximum & Minimum & $\overline{\boldsymbol{X}}$ & S.D \\
\hline Total & 397 & 67 & 191 & 124 & 160.8 & 12.7 \\
\hline
\end{tabular}

The table 1 signifies that the mean score of all the sampled students on the scale of learning styles is 160.82 out of a total score of 200 which is an indication that the respondents use multiple learning styles during their learning process. This is quite obvious because social sciences students have to study a variety of courses that ranges from theoretical descriptions to complex mathematical models. This variety in subjects demands different learning techniques in different scenarios, which suits best to the requirement of the subject. The value of standard deviation shows the possible variations that exist in the attitude towards learning styles among sampled students. 


\section{Macrothink}

International Journal of Learning and Development ISSN 2164-4063 2016, Vol. 6, No. 4

Table 2: Correlation Matrix

\begin{tabular}{|l|l|l|l|l|}
\hline & F1 & F2 & F3 & F4 \\
F1 & I & Converging & Diverging & Accommodating \\
\hline F2 & 0.448 & 0.448 & 0.381 & 0.402 \\
\hline F3 & 0.381 & I & 0.438 & 0.509 \\
\hline F4 & 0.402 & 0.438 & I & 0.574 \\
\hline
\end{tabular}

The table 2 shows that all the four learning styles (or factors), adopted by the students were positively correlated with each other. The correlation coefficient among different learning styles ranges from 0.381 to 0.574 . These values show the moderate relationship between the learning styles practiced by the students. The correlation coefficient between the converging learning style (F2) and the accommodating learning style (F4) was observed to be 0.509 . It is clear from the results that both of these styles are positively related with each other. It shows that students who adopt converging learning styles are more likely to adopt accommodating learning styles. In addition, the highest correlation coefficient of 0.574 was observed between diverging learning style (F3) and accommodating learning style (F4). These results indicate that students who adopt diverging learning style are more likely to adopt accommodating learning style. However, the correlation coefficient was lowest between assimilating and diverging learning styles suggesting that the students who practice assimilating style of learning are least likely to adopt the diverging learning style.

The mean score of each factor is calculated by taking an average of the sum of the student's responses on the attitude scale corresponding to a particular learning style. Additionally, the weight of each factor is calculated by dividing the mean score with the highest possible score of that factor. These statistics are presented in the following table.

Table 3: Comparison between Means

\begin{tabular}{|l|l|l|}
\hline Learning Styles & Mean Score & Weights \% \\
\hline Assimilating & 49.20 & $82 \%$ \\
\hline Converging & 40.21 & $80 \%$ \\
\hline Diverging & 35.37 & $78 \%$ \\
\hline Accommodating & 36.05 & $80 \%$ \\
\hline
\end{tabular}




\section{Mll Macrothink}

International Journal of Learning and Development

ISSN 2164-4063

2016, Vol. 6, No. 4

The above table states the mean scores and the weights of the four learning styles, adopted by the students. The table indicates that assimilating learning style has the highest mean score and weight. Thus, it is the most adopted learning style amongst the sampled students of the three universities. Converging and accommodating were the subsequent preferred learning styles with mean scores of 40.21 and 36.05 respectively. However, diverging learning style have the lowest mean score and weight suggesting that it was the least preferred style in sampled respondents.

Different learning styles can have a different degree of effect on the academic performance of the student. Therefore, it is important to explore that whether there exist any significant difference between learning styles of the three sampled universities.

Table 4: University-wise Comparison of Student's Responses

\begin{tabular}{|l|l|l|l|l|l|}
\hline & Sum of Squares & df & Mean Square & F & Sig. \\
\hline Between Groups & .024 & 2 & .012 & 12.542 & .000 \\
Within Groups & .383 & 394 & .001 & & \\
Total & .407 & 396 & & & \\
\hline
\end{tabular}

The above table presents the university wise comparison of student responses by the use of ANOVA test. This technique is used to identify that is there any significant difference between the mean of different samples. The dependent variable is the student's score of learning styles of three universities that are BZU, UE Multan campus, and IUB. The respective university is taken as an independent variable. The idea is that learning styles of students are supposed to vary across different universities. The analysis reveals that significant difference exists between the mean scores of learning styles of the three sampled universities as suggested by a significant value of F-statistic. These results recommend that students of different universities use different learning styles to accomplish their academic endeavors. These results provide strong support to the argument that teaching strategies and learning environment significantly influence learning approaches of the students. Wheldall states that ways to manage the class will determine the learning environment that teacher subsequently establishes and this will make a difference to what the learners can achieve [20].

\section{Conclusion}

The findings of this study revealed several conclusions. These conclusions are useful in the context of teaching and learning. The majority of students scored higher on the scale that measures learning style adoption of students. This is because of the fact that in learning scenarios, sampled students preferred to adopt a blend of learning styles rather than to be restricted to a single style of learning. The reason is, the field of social sciences like education has a variety of subjects ranging from purely theoretical ones to those involving complex mathematical models. This requires students to obtain learning by using different learning 
styles simultaneously rather than focusing on the single style of learning. Moreover, both converging and diverging approaches towards learning were found to be highly correlated with accommodating learning style revealing that both divergers and convergers are most likely to adopt the accommodating learning styles. These outcomes signify that the higher education students usually practice learning styles that are closely related to each other.

The mean scores of different learning styles demonstrate that assimilating was the most used learning style by the students of the sampled universities. On the contrary, diverging learning style was less practiced by the sampled students. In addition, ANOVA statistics highlighted significant differences in the learning styles of sampled universities. Suggesting that, the university has a strong impact on students in adopting the learning styles. These results are attributed to the fact that universities have differences in course contents and teaching styles in classroom settings. These dissimilarities across universities pose different demands on the students to obtain learning which result in different learning styles adaptation by students across sampled universities.

Based on these conclusions it is recommended that Social science students should focus on adopting multiple learning styles to cope up with the diversity of courses they study. In addition, teaching method should promote those learning styles that optimize the productivity and learning the experience of the students. Moreover, students should focus on a particular learning style that suits best to a specific learning situation because a learning approach that provides better results in one scenario may not be appropriate for another different situation.

\subsection{Future Research Directions}

Future research in this area should focus on the following key dimensions.

The students across different disciplines should be taken as a sample. Because studies from different disciplines suggested different learning styles that are suitable for higher academic performance. Therefore, observing students from different disciplines simultaneously will allow comparative analysis of suitable learning style in different fields of academia.

On the grounds that learning styles of the students differ across universities thus, studies should be designed to determine the influence of teaching methods on the choice of a particular learning style by the students.

\section{References}

[1] Battersby, J., \& Gordon, J. (2006). Preparing to Teach : Learning from Experience. New York: Routledge.

[2] Nisbet, J., \& Shucksmith, J. (1988). Learning Strategies. London: Routledge.

[3] Hoy, W. K., \& Miskel, C. G. (2001). Educational Administration: Theory, Research and Practice (6th ed.). New York: McGraw-Hill.

[4] Smith, R. M. (1988). Learning How to Learn: Applied Theory for Adults. Britsol: Open 
University Press.

[5] Hayes, D., Marshall, T., \& Turner, A. (2007). A Lecturer's Guide to Further Education. London: McGraw-Hill.

[6] Harrison, R. (2005). Learning and Development. Mumbai: Jaico Publishing House.

[7] Kolb, D. (1985). Learning styles inventory. USA.

[8] Shaw, W. T. (2009). Students Learning Style and their Academic Achievement for Taxation Course: A Comparison Study. Proceedings of the 2nd International Conference of Teaching and Learning (ICTL 2009) Malaysia , 1-7.

[9] Abidin, M. J. Z., Rezaee, A. A., Abdullah, H. N., \& Singh, K. K. B. (2011). Learning styles and overall academic achievement in a specific educational system. International Journal of Humanities and Social Science, 1(10), 143-152.

[10] Lieberman, D. A. (2000). Learning: Behavior and Cognition (3rd ed.). Stanford: Wadsworth.

[11] Jaques, D. (2000). Learning in Groups: A Handbook for Improving Group Work (3rd ed.). London: Kogan Page.

[12] Din, M. (2014). A Study in Indices of Discrepancy between Students 'Learning Styles and Their Actual Grade Achievement at Masters'Level. Retrieved from HEC official website: www.hec.gov.pk

[13] Farooq, M. S., \& Regnier, J. C. (2011). Role of learning styles in the quality of learning at different levels. Informatica Economica, 15(3), 28.

[14] Çalışkan, H., \& Kılınç, G. (2012). The Relationship between the Learning Styles of Students and Their Attitudes towards Social Studies Course. Procedia-Social and Behavioral Sciences, 55, 47-56.

[15] Bhatti, R. U., \& Bart, W. M. (2013). On the effect of learning style on scholastic achievement. Current Issues in Education, 16(2).

[16] Akbari, S., Ghanbari, A., \& Talab, M. G. (2013). Learning Styles and Academic Performance of Students in Learning English as a Second Language Class in Iran. Bulgarian Journal of Science and Education Policy, 322-333.

[17] Mohamad, M. M., Heong, Y. M., Hanafi, N. M., \& Kiong, T. T. (2014). Disparity of learning styles and cognitive abilities in vocational education. Int. J. Soc. Hum. Sci. Eng, 8(1), 6-9.

[18] Vaishnav, R. S. (2013). Learning style and academic achievement of secondary school students. Voice of Research, 1(4), 1-4.

[19] Gokalp, M. (2013). The effect of students' learning styles to their academic success. Educational Research and Reviews, 8(17), 1634. 


\section{Macrothink}

International Journal of Learning and Development

ISSN 2164-4063 2016, Vol. 6, No. 4

[20] Wheldall, K. (2010). Developments in Educational Psychology (2nd ed.). New York: McGraw-Hill.

\section{Copyright Disclaimer}

Copyright for this article is retained by the author(s), with first publication rights granted to the journal.

This is an open-access article distributed under the terms and conditions of the Creative Commons Attribution license (http://creativecommons.org/licenses/by/3.0/). 